\title{
Performance Deterioration Analysis of the Used Gear 0il
}

\author{
Qunfeng Zeng1*, Guangneng Dong1, Yanling Yang2, Tonghai Wu' \\ ${ }^{1}$ Key Laboratory of Ministry of Education for Modern Design and Rotor-Bearing System, Xi'an Jiaotong \\ University, Xi'an, China \\ ${ }^{2}$ Jiangxi Key Laboratory of Advanced Copper and Tungsten Materials, Jiangxi Academy of Science, \\ Nanchang, China \\ Email: "zengqf1949@gmail.com
}

Received 22 December 2015; accepted 16 February 2016; published 19 February 2016

Copyright (C) 2016 by authors and Scientific Research Publishing Inc.

This work is licensed under the Creative Commons Attribution International License (CC BY). http://creativecommons.org/licenses/by/4.0/

(c) (†) Open Access

\begin{abstract}
In the present paper, we have investigated the tribological properties and microstructure of the used gear oil theoretically and experimentally. The deterioration process of the in-service gear lubricant oils was also discussed. The viscosity and microstructure of oils running different mileages were analyzed by viscometer and Fourier Transform Infrared Spectroscopy (FTIR), respectively. In addition, the friction and wear behaviors of the friction pair of the GCr15 steel ball and disc were investigated using a ball on disc tribometer under different mileages' gear oils lubrication conditions. These techniques give reproducible and reliable data with which to evaluate the severity of deterioration process of oils. The objective of this work is to understand the deterioration process of gear oil and analyze the influence of deterioration on the performance and microstructure of lubricant oils used in gear box. Possible explanations of deterioration process as well as its influence on friction and wear behaviors are also discussed. The results reveals the tribological properties of used oils depended on strongly the microstructure and its deterioration process of oil.
\end{abstract}

Keywords

Used Gear Oil, Tribological Properties, Viscosity, FTIR, Deterioration

\section{Introduction}

Lubricant oils are important in many industries and essential and expensive components of machine systems es-

"Corresponding author.

How to cite this paper: Zeng, Q.F., Dong, G.N., Yang, Y.L. and Wu, T.H. (2016) Performance Deterioration Analysis of the Used Gear Oil. Advances in Chemical Engineering and Science, 6, 67-75. http://dx.doi.org/10.4236/aces.2016.62008 
pecially in transportation [1]. Lubricant oils are the lifeblood of the gearbox in automobile. It is required to carry out specific functions in order to keep the gearbox running. The basic requirements for gear oils are appropriate viscosity, oxidative and thermal stability, solid load-carrying capacity, demulsibility (ability to shed water), protection against rust and corrosion. Therefore, it's not surprising that users need a thorough grasp of the performance requirements of gear oils. Today's automobile, especially in heavy-duty truck, should handle the increased loads while contending with a host of contaminants, including water. Advanced developments in operating high power and high efficiency engines with significantly high loads require more efficient lubricating technology. To enhance the life of mechanical parts, the usual approach is to replace the lubricant oil periodically. This approach, however, is not desirable because amount of lubricant oils are wasted, which acts as a primary barrier to the development of energy-efficient usage. Therefore, the reasonable replace of lubricant oil with efficient and economic method is considered urgent. Many researchers focused their attention to investigate the performance of the used oils with the conventional technologies and analyze the deterioration process and the failure mechanism of lubricant oils [2] [3]. Lubricant oils in gearbox of heavy duty truck are exposed to depend on the operating conditions, the fuel quality, the ambient conditions and operating parameters. The conditions of the oil are subject to many influences that may degrade its primary function, namely lubrication, to a point where severe damage occurs. Accordingly, the oil itself is an important source of information in the strategy of defect. The rate of deterioration strongly depends on these effects [4]. In order to avoid an engine and axle failure, the lubricant oil must be replaced before it loses its protective properties. At the same time, the unnecessary oil replace should be avoided for environmental and economical reasons [5]. In order to estimate the optimum oil replace interval reliably, it is necessary to investigate the actual physical and chemical condition of the used gear oil. The oil's ageing process is influenced by many factors, such as load, velocity, temperature, the machine parts' material. It is widely acknowledged that the performance deterioration process of the lubricant oil is very complex because even the saturated hydrocarbons, as the major components of lubricant oils, will undergo the complicated chemical changes under actual working conditions. Therefore, especially for axles of heavy-duty truck, the indirect monitoring of the oil condition is essential. The indirect methods mainly relying on the operating parameters such as load and speed, the performance and structure of oil [6]. The used oils are taken in regular intervals for off-line laboratory analysis in order to determine the optimal oil change interval. The entire system should give a reliable indication on the current oil condition and evaluation, when the oil will reach the end of its lifetime and an oil change will be necessary [7]. Previous attempts in the automotive field were based on measuring the permittivity or conductivity of the oil. Although the measurement directly in the oil, these parameters are of the limited use, thus providing a poorly analyzable signals only. The method is the taking off an oil sample for laboratory analysis [8]. A basic advantage of this method is the possibility of obtaining spectra immediately from the gear box of the axle package. The purpose of this method of early failure detection in oil lubricated machinery is to discover the degradation of lubricant oil. The trends include energy-efficient oils and longer-life oils to extend drain and maintenance intervals.

The objective of the present work is to understand the performance deterioration process in order to control and increase the reliability and availability of machinery, while minimizing maintenance costs associated with oil change outs. The viscosity and structure of the used oil were investigated. The tribological properties of the used oil were also performed with three kinds of the used oil running different drive distances. The detailed experiment results are presented. This study is focused on the explanation of the performance deterioration about the structure and lubrication behaviors of the gear oil.

\section{Experimental Details}

\subsection{Oils}

The lubricant oil is $85 \mathrm{~W}-90$ gear oil. The used oils obtained from a heavy duty truck were used as the oil sample for the analysis and measurement. This oil is a gear oil meeting the requirements of axle in heavy truck. The lubricant oil samples were collected at regular drive distance intervals. Three kinds of the used oil were run about $7000 \mathrm{~km}, 30,000 \mathrm{~km}$ and 450,000 km in the same heavy duty truck provided by Shaanxi HanDe Axle Co., Ltd, which indicates the initial running-in period, running-in period and serious wear, respectively.

\subsection{Viscosity of Oil}

The gear oil serves two functions: 1) to remove heat in the machinery generated by friction; and 2) to protect it- 
self from heat-induced viscosity breakdown. The viscosity decreases as the temperature increases, so the viscosity of the oil must be enough high to provide an adequate lubricating film — but not so high that it creates friction within the film itself. With the constant pressure to increase operating loads, gearboxes are burdened with increasingly hotter operating temperatures; so understood the viscosity in gear oil is an imperative. This will help to maximize the life of the gear oil.

The viscosity is one of the most important parameters for the lubrication behaviors of oil. The common viscosity test is the kinematic viscosity method. The kinematic viscosity is the product of the time of flow and the calibration factor of the instrument. The test determines the kinematic viscosity of oils by measuring the time taken for a specific volume of the liquid to flow through a calibrated glass capillary viscometer under specified driving head (gravity) and temperature conditions. The capillary tube is made of quartz glass which has a small thermal expansion coefficient. Once the oil sample has come to temperature, it is allowed to flow down the tube with a predetermined distance. The test is usually performed at the temperature of $100^{\circ} \mathrm{C}$ to standardize the measurement results obtained and allow the comparison among different users. The results are reported as the kinematic viscosity of oils in centistokes (cSt).

\subsection{Oil Analysis}

Typical procedures of the used oil analysis were conducted. The structure of the oil was characterized by Fourier Transform Infrared Spectroscopy (FTIR) to investigate the structure changes in functional group during running. Bruker Tensor27 spectrometer is used to measure the structure of oil in the wave number range $400-4000 \mathrm{~cm}^{-1}$ with $\mathrm{KBr}$ pellet method. All spectra were collected by acquisition of eight scans at a resolution of $4 \mathrm{~cm}^{-1}$ and they were converted to absorbance spectra. The FTIR absorption of the sample was very intense. The sample (1 wt.\%) was mixed with $\mathrm{KBr}$ powders to prepare transparent discs and undergo transmittance IR measurements.

\subsection{Tribological Properties of Oils}

The friction and wear tests were performed using a ball-on-disc rotating-type configuration tribometer to evaluate the tribological properties of the gear oil under boundary lubrication conditions. The ball and disc were securely fastened inside the tribometer chamber, respectively. All friction and wear tests were conducted in the laboratory with $30 \%-35 \%$ of relative humidity and $20^{\circ} \mathrm{C}-25^{\circ} \mathrm{C}$ of room temperature. The disc is high speed steel (HSS). GCr15 steel ball with a diameter of $9.5 \mathrm{~mm}$ is used as the counter pair. The linear velocity is 0.05 $\mathrm{m} / \mathrm{s}$ and the normal load is $10 \mathrm{~N}$, respectively. The initial average Hertzian contact pressure was approximately $1.17 \mathrm{GPa}$, assuming that ball is in direct contact with HSS substrate. These stresses are similar to the maximum stress experienced at the gear contact in the gear reducer of heavy truck. The friction and wear tests were run two and occasionally three times for each combination of the friction pair and a new area on disc and ball was used for each test. Before starting the tests, all the discs and balls were cleaned using acetone in an ultrasonic bath for 10 minutes to eliminate all possible greasy residues from the contact surface, and the surface of disc was pre-lubricated with $10 \mu \mathrm{l}$ of oils, covering the entire surface especially in the possible contact region. Test conditions were selected to create a boundary-lubrication regime, so that the lubrication behaviors of oils were evaluated. After friction and wear tests, the wear scars on the worn disc and ball were both observed and analyzed by optical microscopy.

\section{Results and Discussion}

\subsection{Viscosity of Lubricant Oils}

If the lubricant oil has not the proper viscosity, it cannot perform any of its functions properly. Figure 1 shows the viscosity of the gear oils running different mileages. The viscosity of the fresh oil is $177.4 \mathrm{~mm}^{2} / \mathrm{s}$. The viscosities of the used oil are 162.5, 177.7 and $317.4 \mathrm{~mm}^{2} / \mathrm{s}$ for the drive distances of 7000, 30000 and $45000 \mathrm{~km}$ representing different the wear stages, respectively. The viscosity of the used oil increases with the increase of mileages. However, the viscosity of oil with $7000 \mathrm{~km}$ of mileages is little smaller than that of the fresh oil. The decrease in viscosity is most commonly attributed to molecular cracking (shear) or dilution by a lower viscosity fluid such as fuel or a solvent. The experimental results indicate that the physical properties of oil are different under different mileages. When the viscosity of oil increases, it is usually due to oxidation or degradation. This is the result of the extended oil drain intervals, high operating temperatures, or the presence of water or another 


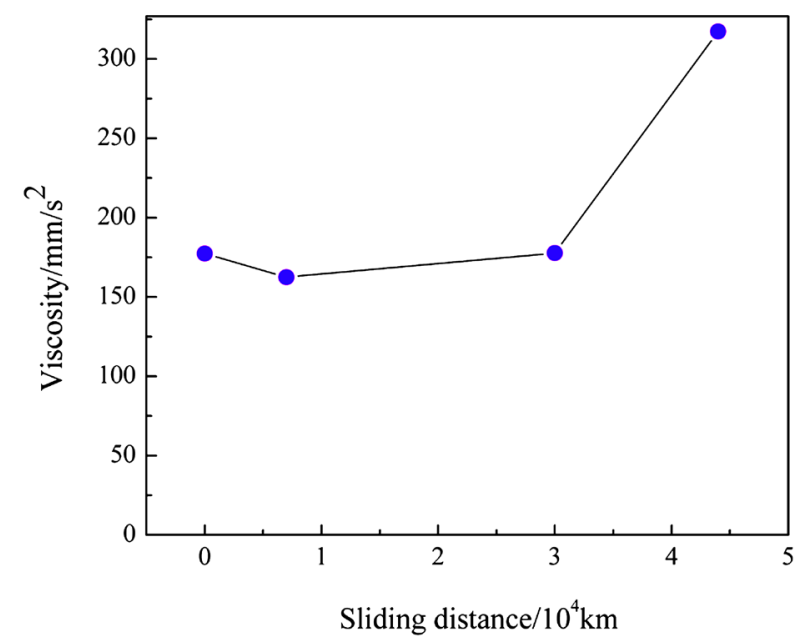

Figure 1. Viscosity of lubricant oil.

oxidation catalyst. The increased viscosity can be the result of excessive contamination with solids such as soot or dirt. In the present work, the contamination may be the wear particles derived from the machine parts during running. The oil cannot adequately protect the component if the contamination is not carried away at the proper rates. Lubricant oil with the improper viscosity will lead to overheating, accelerated wear, and ultimately failure of the component.

\subsection{Analysis of FTIR}

The gear oils are mainly composed of paraffinic, naphthenic, and aromatic molecular structures. The paraffin components of the straight chain are normal-alkanes, where the naphthenic group constitutes of cycloalkanes. They have predominantly six carbons in their ring structures. Aromatics contain at least one ring of six-carbon atoms with alternating single and double bonds. The mono-aromatics are stable in oxidation. However, polyaromatics play an active part in the oxidation process by forming phenols which act as oxidation inhibitors. FTIR analysis of fresh oil is the starting point for further detailed investigations. Figure 2 displays the FTIR curves of the gear oils under different mileages. FTIR spectra results indicate that this gear oil has long-chain alkane. The peaks corresponding to $\mathrm{OH}\left(3600-2500 \mathrm{~cm}^{-1}\right), \mathrm{C}=\mathrm{O}\left(1900-1600 \mathrm{~cm}^{-1}\right)$ and $\mathrm{C}-\mathrm{O}\left(1500-900 \mathrm{~cm}^{-1}\right)$ stretches appear, indicating the presence of secondary products: alcohols, ketones, aldehydes, carboxylic acids and esters. From the intensity of oil's strong band at $1377 \mathrm{~cm}^{-1}$ in FTIR spectroscopy, it was speculated that there is $-\mathrm{CH}_{3}$ group in gear oil [9]. The band at $2925 \mathrm{~cm}^{-1}$ and $2855 \mathrm{~cm}^{-1}$ are assigned to the stretching vibration of $\mathrm{CH}_{2}$ group [10] respectively, which indicates there is also- $-\mathrm{CH}_{2}$ structure within the molecules in gear oil. A weak intensity peak is seen at $721 \mathrm{~cm}^{-1}$, because of the $\mathrm{CH}_{2}$ rocking vibration. FTIR spectroscopy shows the presence of a mixture of heavy paraffin in gear oil. In all tests, regardless of different mileages, FTIR spectra at this range of wave numbers had the similar shape as the spectra recorded in fresh oil. The band at $1300 \mathrm{~cm}^{-1}$ is attributed to $\mathrm{H}-\mathrm{O}-\mathrm{H}$ bending mode, it may be the absorption peak of hydroxyl group in carboxylic acid, which indicates that the gear oil was oxidized and acidized in the operating process. That is to say, it can thus be assumed the oxidation reactions took place during operating, which led to the generation of similar compounds in the used oil. The band at $1078 \mathrm{~cm}^{-1}$ in the used oil with $45000 \mathrm{~km}$ mileage is attributed to the -C-OH stretch. The band at 890 $\mathrm{cm}^{-1}$ in fresh oil is attributed to the -C-H deformation in $-\mathrm{C}=\mathrm{C}-\mathrm{H}$. Moreover, the band at $721 \mathrm{~cm}^{-1}$ in all oils is attributed to the $-\mathrm{CH}_{2}$ - oscillation in an at least five carbon chain, which also indicates gear oil has long chain hydrocarbon. There is a strong band at $3230 \mathrm{~cm}^{-1}$ in FTIR spectroscopy, it may be the absorption peak of hydroxyl group of water molecular. This confirmed that the used oil contained small quantity water. FTIR spectroscopy results showed that the structure of oil was changed with increase of drive distance.

Contamination is most common in gearboxes in heavy truck that handle sand, coal and other environments. Abrasive particles can penetrate the oil film and cause surface distortion and wear. Water contamination can corrode gear surfaces and, in the extreme, destroy a gear completely. Consider that gear oil with just one-percent water content can reduce gear life up to 90 percent, and the damage and contamination can quickly escalate. The 


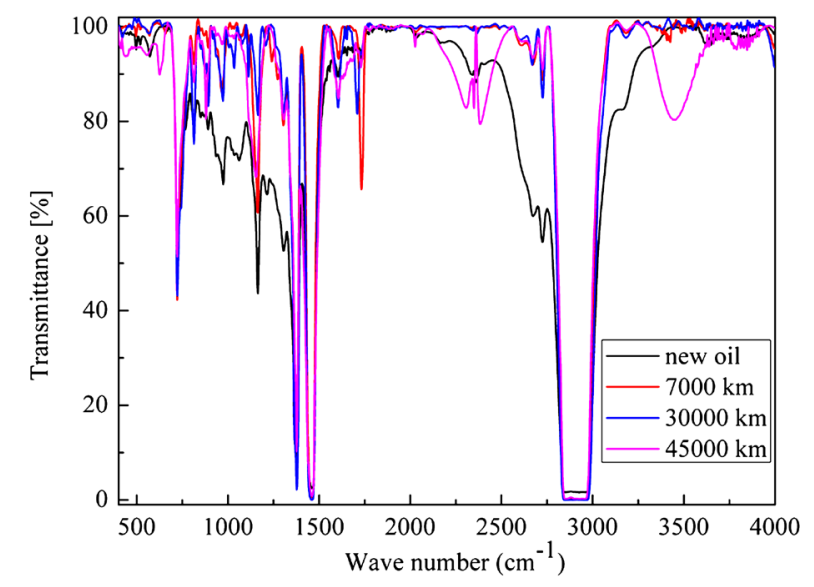

Figure 2. FTIR spectroscopy of lubricant oil.

general trend is toward gears operating under heavier loads and higher temperatures, smaller sumps (lubricant volume) and higher power density. It results in more contamination like abrasive particles and accelerated oxidation. Oxidation is a particular problem for gear oils because it contributes to sludge formation. In attempting to prolong the life of oil in automobile, one is confronted with the opposing trends which arise from the inevitabilities of the lubrication process. A simple single chain hydrocarbon is blended with many other hydrocarbon fractions to make the oil slow down oxidation. This is opposed by the presence of nascent iron debris (from component wear) in the oil. Their presence catalyzes oxidation. The oil was oxidized rapidly, and the life of the base oil is compromised [11].

Lipid radicals are highly reactive and can readily undergo propagation reactions either by abstraction of hydrogen or by reaction with oxygen in its ground state. The following reaction presents the general hydroperoxide generation process where alkyl hydroperoxy radical abstracts hydrogen from the hydrocarbon present in the oil [12].

$$
\begin{aligned}
\mathrm{RH}+\mathrm{R} \leftrightarrow \mathrm{R} \cdot+\mathrm{RH} \\
\mathrm{ROO}+\mathrm{RH} \leftrightarrow \mathrm{ROOH}+\mathrm{R} \cdot \\
\mathrm{R} \cdot+\mathrm{O}_{2} \leftrightarrow \mathrm{ROO} \cdot
\end{aligned}
$$

The oxygenation reaction is fast with almost zero activation energy. Therefore, the concentration of ROO is much higher than that of $\mathrm{R}$ in most oil systems in which oxygen is present. The abstraction of a hydrogen atom by the peroxy radical to generate a hydroperoxide is the rate-determining step of oil oxidation. The rate of reaction 2 depends on the nature of the hydrocarbon (donor) as well as on the nature of the radical (acceptor). The peroxy radicals are relatively stable and only the most weakly bound hydrogen atom. Oil undergoes a series of chain reactions that give peroxides as primary oxidation products, followed by their decomposition to alcohols and ketones under high temperature during running. These products undergo further oxidation and condensation in time, leading to unacceptable acids, esters, and lactones. When time and temperature are two external drivers for change, the process is designated oxidation. Addition of aromatic rings to paraffin, for example, aid oxidation, while the presence of naphthalenes causes an inhibitory effect on oxidation. Because of these frictional forces and wear, as well as contact with the surfaces under extreme conditions, in general, these oils show oxidative degradation tendencies during the lifetime of the lubricant either in storage or during application.

\subsection{Tribological Properties of Oils}

To develop our understanding of the effect of the tribological properties on the oil oxidation and the effect of oil oxidation on the tribological properties, we have investigated the tribological performance of the used gear oil when it is used to lubricate in heavy duty truck using a steel-on-steel sliding interaction. Figure 3 shows average coefficient of friction (COF) of the used oils under different running distances. Table 1 shows COF and diameter of wear scar on the worn ball. The tendency of COF is almost the same in all used oils. The curve of COF is stable, which shows the excellent stability of all oil. There are no significantly changes in COF of the used oil 


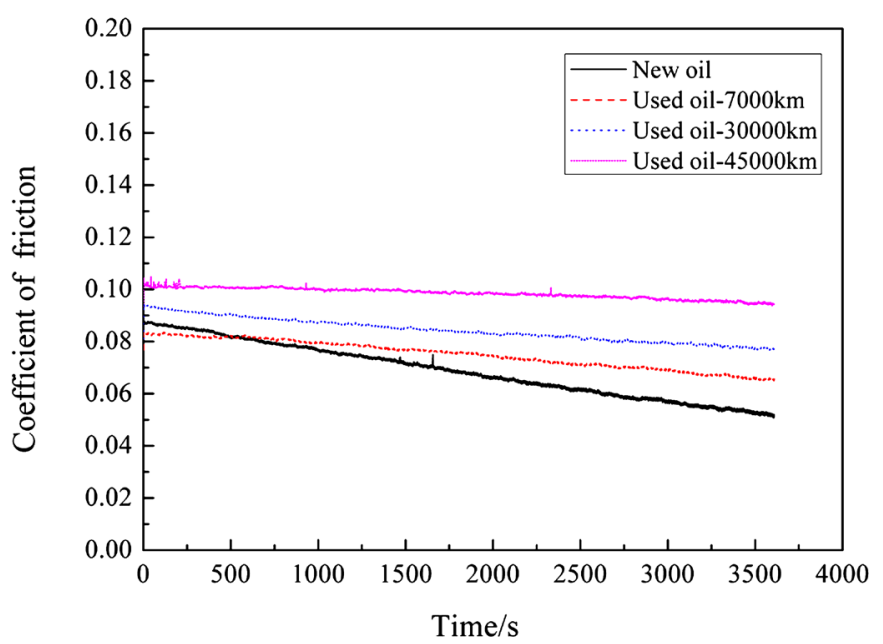

Figure 3. COF of lubricant oil.

Table 1. Average COF of oil and diameter of wear scar.

\begin{tabular}{ccc}
\hline Drive distance $\left(\times 10^{3} \mathrm{~km}\right)$ & Average COF & Diameter of wear scar $(\mu \mathrm{m})$ \\
\hline 0 & 0.058 & 116.88 \\
7 & 0.069 & 119.82 \\
30 & 0.080 & 151.41 \\
45 & 0.096 & 160.46 \\
\hline
\end{tabular}

under different mileages. COF generally increases from 0.058 to 0.096 , which indicates the tribological properties of the used gear oils became deterioration. To investigate the wear mechanism, the worn surface of the ball and flat were ultrasonically washed with both acetone and analyzed using optical microscope. Figure 4 and Figure 5 show that the optical image of wear scar on the ball and flat under different mileages. For the GCr15 steel ball/HSS steel friction pair, the worn surface of flat lubricated by 85W-90 oil didn't appear any visible worn surface morphology. Moreover, the wear scar of the ball is slight in all oils. The experimental results shows that the diameter of the wear scar increases from 116.8 to $160.5 \mu \mathrm{m}$ and the plough became much more with the increase of drive distances. Therefore, it is reasonable to conclude that the microstructure of oil changes during operation, which leads to decrease the lubrication behaviors of the used oil.

Organic species in lubricant oil are subjected to deterioration by oxidation, especially at high temperatures and in the presence of air and metal simultaneously [13]. Oil suffers from oxidation as a result of contact with air at elevated temperatures for long periods and in contact with metals during operation, to form oxygenated compounds that increase the oil viscosity and cause the metal corrosions. Tribology strongly reduces the inception time for oxidation. A possible reason for the difference between the process kinetics of oxidation and the process kinetics of tribooxidation is the catalytic action of soluble iron which gives rise to unstable peroxy radicals. These ions must be present as metal soaps; otherwise they are not catalytically active. The precursor steps of soap formation, shown in reactions 4 - 6 with Fe as the metallic surface, arise from the attack of the metal surface by alkylperoxy radicals and alkyl hydroperoxide. However, during the oil oxidation under the lubrication conditions, the amount of oxygen in lubricant oil is probably less than that in the bulk oil as oxygen is consumed in metal surface oxidation. The oil oxidation process accelerates under lubrication condition because of the catalytic action of soluble iron.

$$
\begin{aligned}
& 2 \mathrm{ROOH} \rightarrow \mathrm{ROO}+\mathrm{R} \cdot+\mathrm{H}_{2} \mathrm{O} \\
& 2 \mathrm{ROOH}+\mathrm{Fe} \rightarrow \mathrm{ROH}+\mathrm{FeO} \\
& \mathrm{ROO}+\mathrm{Fe} \rightarrow \mathrm{RO} \cdot+\mathrm{FeO}
\end{aligned}
$$

From the experimental results and analysis, it is found that the lubrication behaviors of oils can be ascribed to 


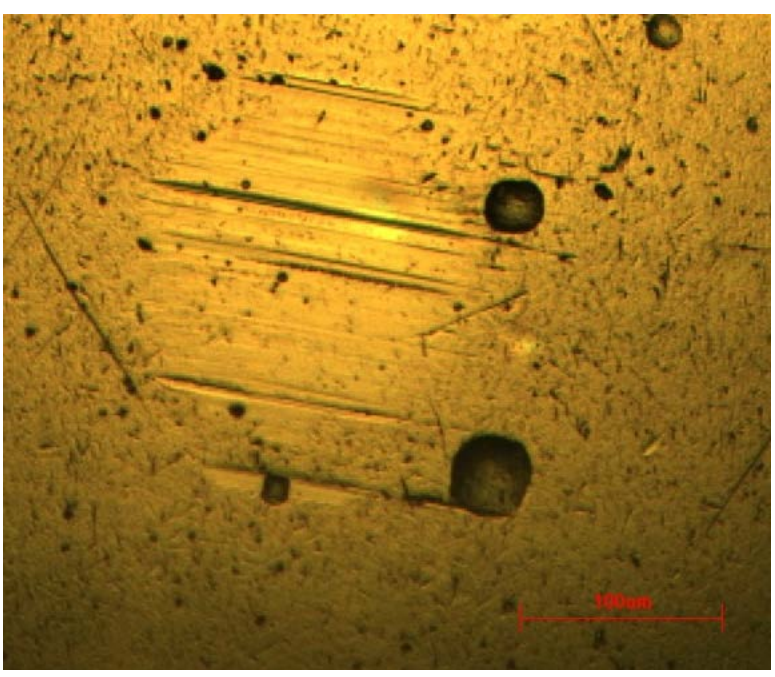

(a)

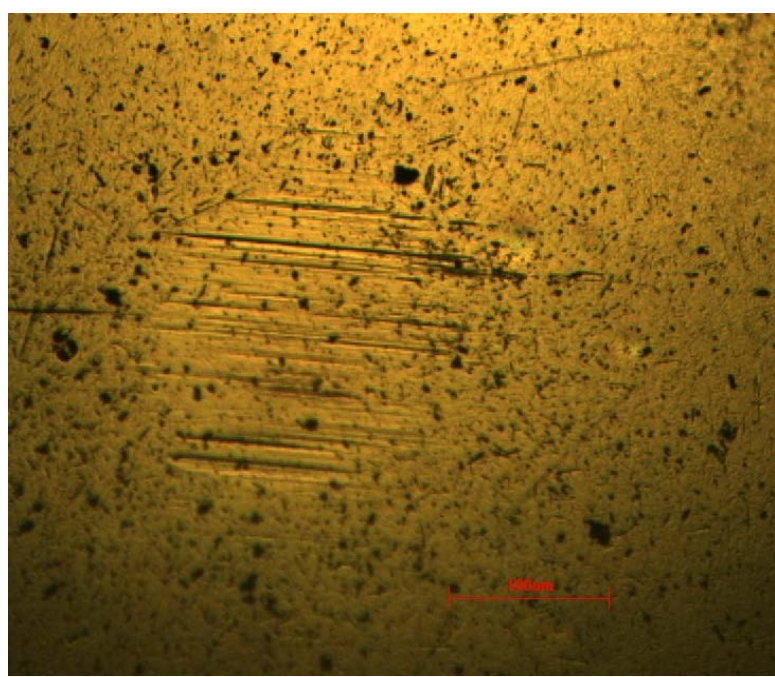

(c)

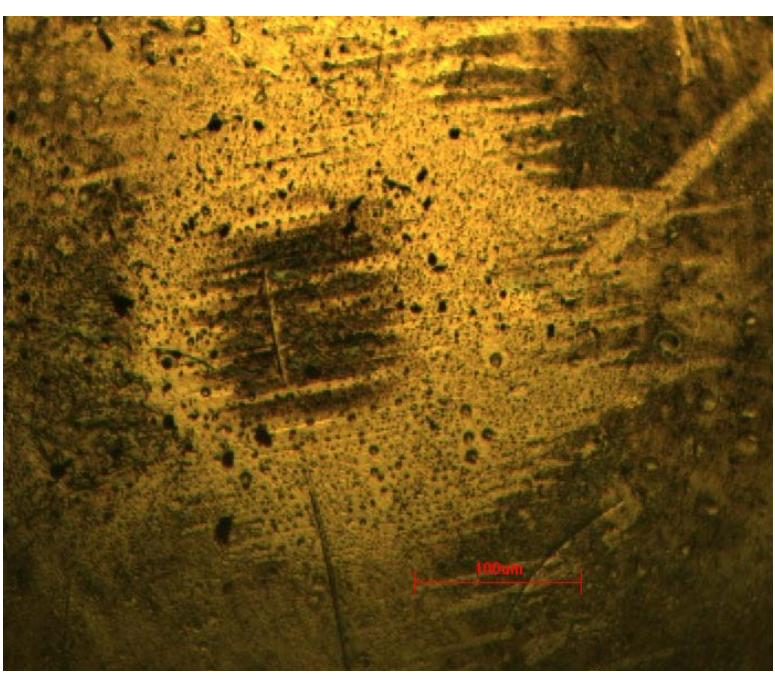

(b)

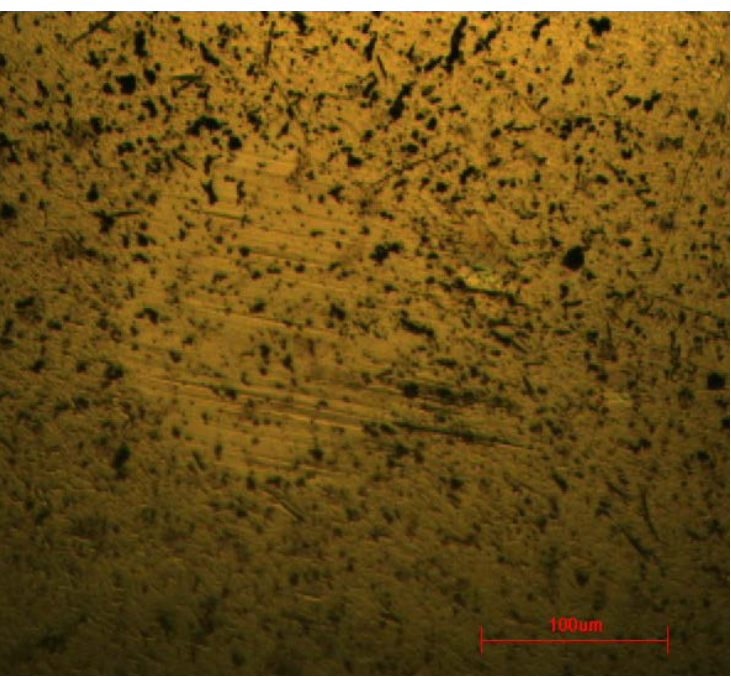

(d)

Figure 4. Optical image of wear scar on ball. (a) Fresh oil; (b) used oil with 7000 km; (c) used oil with 30000 km; (d) used oil with $45000 \mathrm{~km}$.

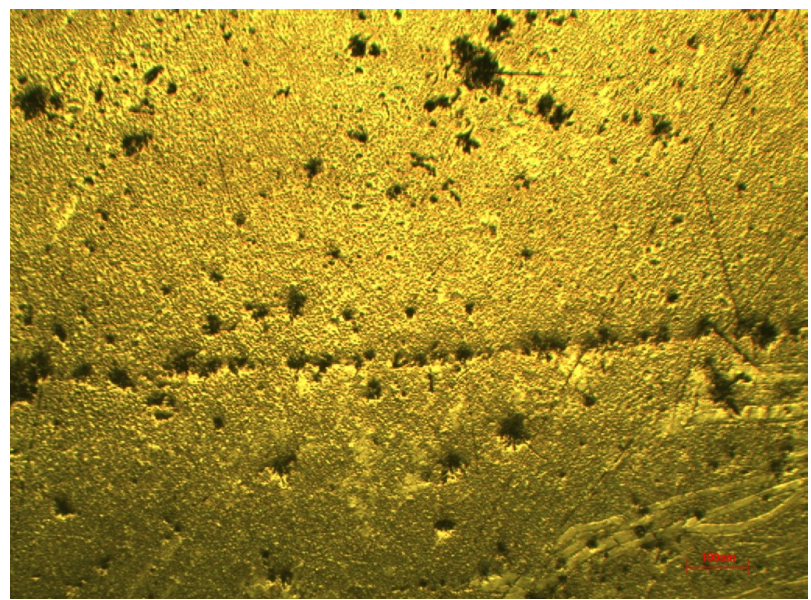

Figure 5. Optical image of wear scar on the flat. 
the structure of oils. Comparison of the spectrum in the used oil with different drive distances shown in Figure 2 led the authors to suppose that the tribochemical reactions occur in oil under dynamic running conditions. The results indicate that there were carboxylic acid, unsaturated compounds and complex compounds in the used oil. For the fresh oil, because pure oil containing highly polar groups adsorbed on the contact surfaces and was not easily removed and effectively decreasing the wear volume. Under the normal heavy duty truck running conditions, the oxidation begin to degrade the lubricant oil resulting in sludge and deposit formation, oil thickening and an increase in oil acidity. Therefore, the structure and viscosity of the used oil was changed, the lubrication behaviors of the used oil was also deteriorated.

Oxidative or per oxidative attack is occurred on the metal to form the removable oxides. The rate of oxidation of lubricant oil when used as a lubricant may be significantly different from the rate of oxidation. The mechanism of oxidation is also found to be altered when tribology is imposed, necessitating a process designation of "tribooxidation". The metal may exist in lubricant oil as oil-soluble organometallic salts or fresh solid particles. The catalytic action of a metal to promote the oil oxidation is metal specific. Compounds of copper, lead, and iron and so on have large accelerating affected on the overall rate of the oil oxidation. In most practical lubricating situations the presence of metal in oil is ubiquitous. The metal comes from the wear of the machine parts during operation. The effects of soluble iron on hydrocarbon oxidation depend very much on its concentration. The antioxidant activity of copper happens because of a recycling process in which $\mathrm{Fe}^{2+}$ and $\mathrm{Fe}^{3+}$ species are involved repeatedly in termination reactions with peroxy and alkyl radicals, and redox reactions with soluble iron. The useful life of the oil is determined by its oxidative stability, which is enhanced by hydrogenation of the base oil and addition of various oxidation inhibitors. The physical and chemical complexity of these systems, however, creates difficult-to-control reaction pathways, kinetics, and mechanisms.

\section{Conclusions}

In the present paper we have investigated three parameters as the viscosity, microstructure and tribology of used gear oil. A series of the used gear oil was prepared under different mileages from heavy duty truck. The microstructure and the tribological properties of the used gear oils were investigated systemically. The following conclusions can be drawn from the experimental results and analysis.

(1) The viscosity of the used gear oils increases and the microstructure of oil changes with the increase of mileages. The used gear oils was oxidized and even acidized under the dynamic driving condition.

(2) The tribological properties of the used gear oils are consistent with their microstructure. The tribological properties of the used gear oils become worsen due to the changed microstructure of the used oil. The used gear oil has a slight increase in COF, and COF increases with the increase of the mileages.

(3) The oxidation of used gear oils is accelerated because of the catalytic action of iron which is the more important driver of oxidation action. The present study provides an understanding of the oxidation process affecting the performance of the lubricant oil.

\section{Acknowledgements}

The authors would like to express their gratitude to National Natural Science Foundation of China (Nos. 51305331 and 51275381) for the financial support.

\section{References}

[1] Zeng, Q., Yu, F. and Dong, G. (2013) Superlubricity Behaviors of $\mathrm{Si}_{3} \mathrm{~N}_{4}$ /DLC Films under PAO oil with Nano Boron Nitride Additive Lubrication. Surface and Interface Analysis, 45, 1283-1290. http://dx.doi.org/10.1002/sia.5269

[2] Raadnui, S. and Kleesuwan, S. (2005) Low Cost Condition Monitoring Sensor for Used Oil Analysis. Wear, 259, 1502-1506. http://dx.doi.org/10.1016/j.wear.2004.11.009

[3] Abdulkareem, A.S., Afolabi, A.S., Ahanonu, S.O., et al. (2014) Effect of Treatment Methods on Used Lubricating Oil for Recycling Purposes. Energy Sources, Part A: Recovery, Utilization, and Environmental Effects, 36, $966-973$. http://dx.doi.org/10.1080/15567036.2010.549920

[4] Al-Ghouti, M.A., Al-Degs, Y.S. and Amer, M. (2010) Application of Chemometrics and FTIR for Determination of Viscosity Index and Base Number of Motor Oils. Talanta, 81, 1096-1101. http://dx.doi.org/10.1016/j.talanta.2010.02.003

[5] Barret, M. and Stover, J. (2005) Understanding Oil Analysis and How It Can Improve the Reliability of Wind Turbine 
Gearboxes. Insight Services, CC Jensen, Inc., 1-12.

[6] Usman, M.A. and Kayode-Sote, O.G. (2011) Reclamation of Used Lubricating Oils. Petroleum \& Coal, 53, $159-166$.

[7] Zhang, L.T., Car, G.X., Wang, Y.L. and Eli, W.J. (2012) Synthesis and Characterization of Antioxidant Modified Esters of Dipentaerythritol as Lubricating Base Oil. Lubrication Science, 24, 228-237.

[8] Van De Voort, F.R., Sedman, J., Cocciardi, R.A. and Pinchuk, D. (2006) FTIR Condition Monitoring of in Service Lubricants: Ongoing Developments and Future Perspertives. Tribology Transactions, 49, 410-418. http://dx.doi.org/10.1080/10402000600781432

[9] Cann, P.M. and Spikes, H.A. (2005) In Contact IR Spectroscopy of Hydrocarbon Lubricants. Tribology Letters, 19, 289-297. http://dx.doi.org/10.1007/s11249-005-7446-4

[10] Jia, Z.F., Su, Y.C., Xia, Y.Q., Shao, X., Song, Y.X., Ni, J.J. and Ma, J. (2013) Synthesis Characterization and Tribological Behavior of Oleic Acid Capped Calcium Borate Hydrate. Tribology Transactions, 56, 521-529. http://dx.doi.org/10.1080/10402004.2013.763392

[11] Ofunne, G.C., Maduako, A.U. and Ojinnaka, C.M. (1991) Studies on the Effects of Temperature on the Chemical Characteristics of Automotive Crankcase Oils and Their Base Oils. Tribology International, 24, 173-178. http://dx.doi.org/10.1016/0301-679X(91)90023-3

[12] Bari, S., Yu, C.W. and Lim, T.H. (2002) Performance Deterioration and Durability Issues While Running a Diesel Engine with Crude Palm Oil. Proceedings of the Institution of Mechanical Engineers, Part D: Journal of Automobile Engineering, 216, 785-792. http://dx.doi.org/10.1243/09544070260340871

[13] Singh, A., Gandra, R.T., Schneider, E.W. and Biswas, S.K. (2013) Studies on the Aging Characteristics of Base Oil with Amine Based Antioxidant in Steel-on-Steel Lubricated Sliding. The Journal of Physical Chemistry C, 117, 1735-1747. http://dx.doi.org/10.1243/09544070260340871 